\title{
Model Pembelajaran Kooperatif Tipe STAD ( Student Teams Achievement Division) dalam Pembelajaran MI
}

\author{
Innayah Wulandari
}

Institut Agama Islam Negeri Kudus, Indonesia

$\bowtie$ E-mail: innayahwulandari895@gmail.com

\begin{abstract}
Abstrak
Penelitian ini bertujuan untuk mengetahui model pembelajaran kooperatif tipe STAD secara umum, metode penelitian yang digunakan adalah metode kepustakaan. Pengumpulan data menggunakan studi kepustakaan dengan metode yang akan digunakan untuk tinjauan pustaka ini. Data yang diperoleh dikumpulkan, dianalisis dan disimpulkan mengenai studi kepustakaan. Penelitian ini membahas tentang pemahaman model pembelajaran kooperatif tipe STAD, karakteristik model pembelajaran kooperatif tipe STAD, langkah-langkah model pembelajaran kooperatif tipe STAD, dan tahapantahapan model pembelajaran kooperatif tipe STAD. Jadi, kita bisa mengetahui model pembelajaran kooperatif tipe STAD secara umum, Yaitu pembelajaran kooperatif tipe STAD suatu model pembelajaran dimana peserta didik belajar dan bekerja sama dalam kelompok kecil yang secara kolaboratif anggotanya 4-5 orang dengan struktur kelompok heterogen. Bisa juga menentukan langkah- Langkah model pembelajarannya secara tepat, serta dapat menentukan apakah dalam pembelajaran tertentu bisa digunakan oleh guru dalam mengajar dengan menggunakan model pembelajaran kooperatif tipe STAD ini atau tidak cocok digunakan dalam pembelajaran.
\end{abstract}

Kata Kunci: Model Pembelajaran Kooperatif tipe STAD; Guru; MI

\begin{abstract}
This study aims to determine the STAD type cooperative learning model in general, the research method used is the library method. Collecting data using literature study, the method that will be used for this literature review. The data obtained were collected, analyzed and concluded about the literature study. Library research is a research that has the same arrangement as other research, but the sources and methods of data collection are by taking library data, reading, taking notes, and processing research materials. This study discusses the understanding of the STAD type cooperative learning model, the characteristics of the STAD type cooperative learning model, the steps of the STAD type cooperative learning model, and the stages of the STAD type cooperative learning model. So, we can find out the STAD type cooperative learning model in general, That is cooperative learning type STAD a learning model in which students learn and work together in small groups collaboratively consisting of 4-5 people with a heterogeneous group structure. It can also determine the steps of the learning model appropriately, and can also determine whether in certain learning the teacher can use it in teaching using this STAD type cooperative learning model or not suitable for use in learning.
\end{abstract}

Keywords: Cooperative Learning Model type STAD; Teachers; MI. 


\section{PENDAHULUAN}

Pendidikan formal diterapkan dasardasar ilmu pengetahuan, kepribadian, moral, pembentukan watak, dengan begitu pemberian dasar ilmu yang positif akan berpengaruh terhadap kualitas pendidikan yang lebih baik, ke jenjang pendidikan selanjutnya. Dengan begitu dapat melakukan pergeseran paradigma dalam proses pembelajaran, seperti perubahan orientasi pembelajaran dengan adanya guru sebagai fasilitator.

Pembelajaran ini yang awalnya berpusat ke guru, menjadi pembelajaran berpusat kesiswa. Sehingga, guru harus menciptakan suasana belajar yang melibatkan interaksi yang baik antara guru dengan siswa, siswa yang satu dengan siswa yang lainnya. Dalam menciptakan interaksi yang baik. Diperlukan adanya usaha membangkitkan serta mengembangkan keaktifan belajar siswa. Keaktifan siswa ini menentukan keberhasilan tujuan pembelajaran. maka, harus ada guru yang profesional.

Keberhasilan dalam pembelajaran didukung oleh strategi atau metode yang digunakan. Penggunaan strategi dalam pembelajaran sangat penting karena, untuk mempermudah dalam belajar sehingga, dapat mencapai hasil yang optimal. Tanpa strategi pembelajaran tidak akan optimal, dan tidak akan berlangsung secara efektif dan efesien.

Penggunaan strategi guru memiliki peran yang penting. Seorang guru mampu memilih dan menerapkan strategi pembelajaran untuk siswa dengan baik agar proses belajar berjalan dengan baik. Guru juga harus memiliki wawasan yang luas mengenai strategi pembelajaran. Dengan demikian guru akan mudah menentukan strategi pembelajaran yang akan digunakan dalam proses belajar mengajar. Jika guru mempunyai strategi yang tepat maka, kegiatan belajar mengajar siswa akan berjalan sesuai ketentuan, serta siswa dapat lebih cepat memahami materi yang disampaikan oleh guru. Dengan demikian, keberhasilan dalam pembelajaran akan mudah tercapai dengan baik sesuai harapan.

Pembelajaran student teams achievement division (STAD) merupakan salah satu tipe pembelajaran kooperatif yang menekankan interaksi diantara siswa untuk saling memotivasi dan saling membantu dalam menguasai materi dan mencapai prestasi secara maksimal. Atau yang disebut Dengan bekerja kelompok siswa akan lebih bebas bertanya terhadap teman kelompoknya tentang materi yang belum dikuasainya. Dalam satu kelas siswa terbagi menjadi beberapa kelompok tergantung kapasitas siswa yang terdiri dari 4-5 siswa tiap kelompoknya. tujuan strategi ini agar masing-masing siswa merasa bahwa mereka adalah satu dan seperjuangan. Sedangkan jika salah satu kelompok dapat memenuhi kriteria yang ditentukan, kelompok tersebut akan mendapatkan penghargaan.

Artikel ini akan membahas mengenai pengertian model pembelajaran kooperatif tipe STAD, karakteristik model pembelajaran kooperatif tipe STAD, langkah-langkah model pembelajaran kooperatif tipe STAD, serta Fase-fase pembelajaran Kooperatif tipe STAD.

\section{METODE PENELITIAN}

Metode penelitian yang digunakan yaitu Metode literatur. Pengumpulan data ialah Studi pustaka, metode yang akan digunakan untuk pengkajian literatur ini. Data yang diperoleh dikompulasi, dianalisis dan disimpulkan mengenai studi literatur. Penelitian literatur merupakan penelitian yang persiapannya sama dengan penelitian 
lainnya akan tetapi sumber dan Metode pengumpulan data dengan mengambil data pustaka, membaca, mencatat, dan mengolah bahan penelitian.

\section{HASIL DAN PEMBAHASAN}

Anak MS memiliki jenis ketunaan anak lamban belajar. Anak lamban belajar dikenal dengan istilah slow learners, backward, dull, atau borderline. Mumpuniarti (2007: 14) mengidentifikasi anak lamban belajar sebagai anak yang mempunyai IQ di antara 70 sampai 89.

Menurut pendapat slavin Pembelajaran STAD merupakan model pembelajaran tipe kooperatif, guru membagi siswa menjadi beberapa kelompok yang terdiri dari 4-5 orang yang terdiri dari laki-laki maupun perempuan, yang memiliki kemampuan berbeda-beda (Esminarto:2016). Pendapat dari Trianto pembelajaran STAD ialah salah satu tipe model pembelajaran kooperatif dengan menggunakan kelompok kecil dengan jumlah anggota setiap kelompok 4-5 peserta didik yang terdiri atas berbagai unsur yang berbeda sifat serta berlainan jenis (Rakhmawan:2014).

Pembelajaran kooperatif tipe STAD adalah model pembelajaran untuk tempat siswa belajar dalam kelompok kecil yang terdiri dari 4-5 siswa dengan tingkatan kemampuan siswa yang berbeda, untuk menguasai materi dalam menyelesaikan tugas kelompok setiap anggota saling bekerja sama secara kolaboratif dan membantu memahami materi, serta membantu teman untuk menguasai bahan pembelajaran. Student Teams-Achievement Divisions (STAD) berarti mengerjakan sesuatu secara bersama-sama dengan saling membantu satu dengan yang lain sebagai satu tim.

Erman mengemukakan bahwa, "Model student teams achievement division (STAD) tergolong pada model pembelajaran kooperatif, yaitu model pembelajaran yang terdiri atas kelompok kecil yang bekerja sama sebagai satu tim untuk memecahkan masalah, melengkapi tugas atau menyelesaikan tugas bersama". Dengan demikian, model student teams achievement division (STAD) merupakan model pembelajaran yang dapat merangsang aktivitas siswa untuk mengemukakan pendapat, ide, dan gagasan dalam pembelajaran (Maulana, panji:2017).

Pembelajaran kooperatif tipe STAD, bekerja dalam kelompok sehingga siswa dapat menumbuhkan kemauan kerja sama, berpikir kritis, termotivasi, bertanggung jawab terhadap kelompok. Siswa memiliki kemampuan untuk membantu teman dan terhadap diri sendiri dalam mengikuti kuis nantinya guna mencapai suatu tujuan yaitu mendapatkan penghargaan tim yang super. Adanya evaluasi, siswa mampu merangkum pelajaran yang diterima dari penjelasan guru maupun hasil kerja kelompok yang dilakukan. Guru mengevaluasi hasil belajar tentang materi yang telah dipelajari dimana siswa tidak diperbolehkan bekerja sama (Wardana, Ika: 2017).

Model pembelajaran ini memacu kerja sama siswa melalui belajar dalam kelompok yang anggotanya beragam agar saling mendorong dan membantu satu sama lain dalam suasana social yang beragam untuk menguasai keterampilan yang sedang dipelajari. Dari pengertian diatas dapat disimpulkan pembelajaran kooperatif tipe STAD merupakan suatu model pembelajaran dimana peserta didik belajar dan bekerja sama dalam kelompok kecil yang secara kolaboratif anggotanya 4-5 orang dengan struktur kelompok hiterogen.

Model STAD lebih mementingkan sikap partisipasi peserta didik dalam 
mengembangkan potensi kognitif dan efektif antara lain: (1) relatif mudah menyelenggarakannya, (2) mampu memotivasi siswa dalam mengembangkan potensi individu, terutama kreatifitas dan tanggung jawab dalam mengangkat citra kelompoknya, (3) melatih siswa untuk bekerja sama dan saling tolong menolong dalam kelompok, (4) siswa mampu menyakinkan dirinya dan orang lain bahwa tujuan yang ingin dicapai bergantung pada cara kerja mereka, bukan karena keberuntungan, (5) siswa mampu berkomunikasi verbal dan nonverbal dalam bekerja sama, (6) meningkatkan keakraban antar siswa.

Karakteristik model pembelajaran kooperatif tipe STAD antara lain :

1) Pembelajaran secara tim. Setiap anggota tim mampu membuat setiap siswa belajar, setiap tim harus bekerja sama untuk mencapai tujuan pembelajaran. Kriteria keberhasilan pembelajaran ditentukan keberhasilan keberhasilan tim. Setiap kelompok bersifat heterogen. Agar setiap anggota memberikan kontribusi terhadap keberhasilan kelompok.

2) Didasarkan pada manajemen kooperatif. Dalam manajemen kooperatif memiliki empat imigsi pokok antara lain fungsi perencanaan, fungsi organisasi, fungsi pelaksanaan serta fungsi kontrol. 3) Keterampilan Bekerja Sama. Kemauan untuk bekerja sama itu kemudian dipraktikkan melalui aktivitas dan kegiatan yang tergambarkan dalam keterampilan bekerja sama. Dengan demikian, siswa perlu didorong untuk mau clan sanggup berinteraksi dan berkomunikasi dengan anggota lain. Siswa perlu dibantu mengatasi berbagai hambatan dalam berinteraksi dan berkomunikasi, sehingga setiap siswa dapat menyampaikan ide, mengemukakan pendapat, dan memberikan kontribusi kepada keberhasilan kelompok.

Model pembelajaran STAD merupakan salah satu model pembelajaran yang telah digunakan dalam berbagai mata pelajaran seperti matematika, bahasa, seni, IPA, sampai IPS dan Pendidikan Agama Islam. Model pembelajaran ini pada tataran implementasinya menggunakan pembauran kemampuan empat anggota kelompok yang berbeda, yakni pembelajaran interaksi normatif, dilakukan dengan sadar dan bertujuan, dan menjadi pedoman ke arah mana tujuan pendidikan akan diarahkan.

Selain itu juga Model pembelajaran Cooperative Learning Student Teams Achievement Division (STAD) dapat diterapkan untuk memotivasi siswa yang berani mengemukakan pendapatnya, menghargai pendapat orang lain/teman, dan saling memberikan pendapat (sharing ideal), selain itu dalam belajar biasanya siswa dihadapkan pada latihan soal-soal atau pemecahan masalah. Oleh karena itu pembelajaran kooperatif sangat baik untuk dilaksanakan karena siswa dapat bekerja sama dan saling tolong menolong dalam menghadapi tugas yang dihadapi.

Langkah-langkah model pembelajaran STAD (Student Teams Achievement Division), yaitu: (1) Membentuk kelompok yang anggotanya empat orang secara heterogen (campuran menurut prestasi, jenis kelamin, suku, dan lain-lain). (2) Guru menyajikan pelajaran. (3) Guru memberi tugas kepada kelompok untuk dikerjakan oleh anggota- anggota kelompok. Anggotanya yang sudah mengerti dapat menjelaskan pada anggota lainnya sampai semua anggota dalam kelompok itu mengerti. (4) Guru memberi kuis atau pertanyaan kepada seluruh peserta didik. (5) Memberi evaluasi,. (6) Kesimpulan. 
Model pembelajaran STAD, peserta didik diberi kesempatan untuk berkomunikasi dan berinteraksi sosial dengan temannya untuk mencapai tujuan pembelajaran, sementara guru bertindak sebagai motivator dan fasilitator peserta didik (Agus Suprijono: 2011).

Menurut trianto Fase-fase pembelajaran Kooperatif tipe STAD ( Student Teams Achievement Division) Fase Kegiatan Guru Antara lain:

Fase 1 Menyampaikan tujuan dan memotivasi siswa Menyampaikan semua tujuan pelajaran yang ingin dicapai pada pelajaran tersebut dan memotivasi siswa belajar.

Fase 2 Menyajikan/ menyampaikan informasi Menyajikan informasi kepada siswa dengan jalan mendemonstrasikan atau lewat bahan bacaan.

Fase 3 Mengorganisasikan siswa dalam kelompok-kelompok belajar Menjelaskan kepada siswa bagaimana cara membentuk kelompok belajar dan membantu setiap kelompok agar melakukan transisi secara efisien.

Fase 4 Membimbing kelompok bekerja dan belajar Membimbing kelompok kelompok belajar pada saat mereka mengerjakan tugas mereka.

Fase 5 Evaluasi Mengevaluasi hasil belajar tentang materi yang telah diajarkan atau masing-masing kelompok mempresentasikan hasil kerjanya. Fase 6 Memberikan penghargaan Mencari cara-cara untuk menghargai baik upaya maupun hasil belajar individu dan kelompok.

Menurut Slavin kelebihan model pembelajaran STAD adalah sebagai berikut: Setiap siswa memiliki kesempatan untuk memberikan kontribusi yang substansial kepada kelompok dan posisi anggota kelompok. Menggalakan interaksi secara akti dan positif sehingga bentuk kerjasama anggota kelompok yang menjadi lebih baik. Membantu siswa untuk memperoleh hubungan pertemanan lintas ras, suku, agama, gender, kemampuan akademIs yang lebih banyak dan beragam (Slavin, Robert.E: 2015).

Kelebihan model pembelajaran STAD (Student Teams Achievement Division): (1) Siswa bekerja sama dalam mencapai tujuan dengan menjunjung tinggi norma-norma kelompok, (2) Siswa aktif membantu dan memotivasi semangat untuk berhasil bersama, (3) Aktif berperan sebagai tutor sebaya untuk lebih meningkatkan keberhasilan kelompok, (4) Interaksi antar siswa seiring dengan peningkatan kemampuan mereka dalam berpendapat.

Sedangkan kelemahan dalam penerapan model pembelajaran kooperatif tipe STAD menurut Kurniasih yakni sebagai berikut:

1. Bila ditinjau dari sarana kelas, maka mengatur tempat duduk untuk kerja kelompok sangat menyita waktu. Hal ini biasanya disebabkan belum tersedianya ruangan-ruangan khusus yang memungkinkan secara langsung dapat digunakan untuk belajar kelompok.

2. Jumlah siswa yang besar (kelas gemuk) dapat menyebabkan guru kurang maksimal dalam mengamati kegiatan belajar, baik secara kelompok maupun secara perorangan.

3. Guru dituntut bekerja cepat dalam menyelesaikan tugas-tugas yang berkaitan dengan pembelajaran yang dilaksanakan, di antaranya mengoreksi pekerjaan siswa, menghitung skor perkembangan maupun menghitung skor rata-rata kelompok yang harus dilakukan pada setiap akhir pertemuan.

4. Menyita waktu yang banyak dalam mempersiapkan pembelajaran (Kurniasih, 
Imas dan Sani, Berlin: 2015).

Kelemahan dalam penggunaan model pembelajaran STAD (Student Teams Achievement Division) sebagai berikut:

1. Sejumlah siswa mungkin banyak yang bingung karena belum terbiasa dengan perlakuan seperti ini.

2. Membutuhkan waktu yang lebih lama untuk siswa sehingga sulit mencapai target kurikulum.

3. Membutuhkan waktu yang lebih lama untuk guru sehingga pada umumnya guru tidak mau menggunakan pembelajaran kooperatif tipe STAD.

4. Membutuhkan kemampuan khusus guru sehingga tidak semua guru dapat melakukan pembelajaran kooperatif STAD. 5.Menuntut sifat tertentu dari siswa, misalnya sifat suka bekerja sama ( Ariani, Tri: 2018).

Model STAD (Student Team Achievement Division) berarti divisi prestasi tim siswa. STAD adalah model pembelajaran kooperatif yang memacu kerjasama siswa melalui belajar dalam kelompok yang anggotanya beragam untuk menguasai keterampilan yang sedang dipelajari.

\section{UCAPAN TERIMA KASIH}

Ucapan terimakasih diperuntukkan bagi publikasi penelitian dengan skema penelitian untuk tugas mata kuliah karya tulis ilmiah Oleh karena itu, penulis mengucapkan terimakasih kepada DPRM DIKTI atas dukungan pendanaannya demi kesuksesan penelitian ini.

\section{KESIMPULAN}

Pembelajaran kooperatif tipe STAD merupakan suatu model pembelajaran dimana peserta didik belajar dan bekerja sama dalam kelompok kecil yang secara kolaboratif anggotanya 4-5 orang dengan struktur kelompok hiterogen.
Karakteristik model pembelajaran kooperatif tipe STAD antara lain; (1) Pembelajaran secara tim, (2) Didasarkan pada manajemen kooperatif, Keterampilan Bekerja Sama.

Langkah-langkah/ sintaks model pembelajaran STAD, yaitu: (1) Membentuk kelompok yang anggotanya empat orang secara heterogen (campuran menurut prestasi, jenis kelamin, suku, dan lain-lain), (2) Guru menyajikan pelajaran, (3) Guru memberi tugas kepada kelompok untuk dikerjakan oleh anggota- anggota kelompok. (4) Guru memberi kuis atau pertanyaan kepada seluruh peserta didik, (5) Memberi evaluasi, (6) Kesimpulan.

Fase-fase pembelajaran Kooperatif tipe STAD Fase Kegiatan Guru; Fase 1 Menyampaikan tujuan dan memotivasi siswa, Fase 2 Menyajikan/ menyampaikan informasi, Fase 3 Mengorganisasikan siswa dalam kelompok-kelompok belajar, Fase 4 Membimbing kelompok bekerja dan belajar, Fase 5 Evaluasi, Fase 6 Memberikan penghargaan.

Kelebihan model pembelajaran STAD: (1) Siswa bekerja sama dalam mencapai tujuan dengan menjunjung tinggi normanorma kelompok, (2) Siswa aktif membantu dan memotivasi semangat untuk berhasil bersama, (3) Aktif berperan sebagai tutor sebaya untuk lebih meningkatkan keberhasilan kelompok,(4) Interaksi antar siswa seiring dengan peningkatan kemampuan mereka dalam berpendapat.

Kelemahan dalam penggunaan model pembelajaran STAD sebagai berikut: 1 . Sejumlah siswa mungkin banyak yang bingung karena belum terbiasa dengan perlakuan seperti ini. 2. Membutuhkan waktu yang lebih lama untuk siswa sehingga sulit mencapai target kurikulum, 3. Membutuhkan waktu yang lebih lama untuk guru sehingga 
pada umumnya guru tidak mau menggunakan pembelajaran kooperatif tipe STAD, 4. Membutuhkan kemampuan khusus guru sehingga tidak semua guru dapat melakukan pembelajaran kooperatif STAD, 5. Menuntut sifat tertentu dari siswa, misalnya sifat suka bekerja sama

\section{DAFTAR RUJUKAN}

Budiwibowo, S. (2018). Manajemen Pendidikan. Yogyakarta.

Esminarto, E., Sukowati, S., Suryowati, N., \& Anam, K. (2016). Implementasi Model Stad dalam Meningkatkan Hasil Belajar Siwa. BRILIANT: Jurnal Riset dan Konseptual, 1(1), 16-23.

Rakhmawan,dedi, Julianto, (2014). Penerapan model kooperatif tipe stad untuk meningkatkan hasil pada sekolah dasar. Vol. 02, no.03.. Hal 3-5.

Zulhartati, sri. Pembelajaran Kooperatif Model Stadpada Mata Pelajaran IPS. https://media.neliti.com/media/publicat ions/218170-pembelajaran-kooperatifmodel-stad-pada.pdf.

Maulana, P., \& Akbar, A. (2017). Penerapan Pembelajaran Kooperatif Tipe STAD (Student Team Achievement Division) untuk Meningkatkan Kemampuan Membaca Pemahaman di Sekolah Dasar. Jurnal Pesona Dasar, 5(2).

Wardana, I., Banggali, T., \& Husain, H. (2017). Penerapan model pembelajaran kooperatif tipe student team achivement division (STAD) untuk meningkatkan hasil belajar siswa kelas XI IPA Avogadro SMA Negeri 2 Pangkajene (Studi pada Materi Asam Basa). Chemica: Jurnal Ilmiah Kimia dan Pendidikan Kimia, 18(1), 76-84.

Kasmawati, K. (2018). Implementasi Pembelajaran Kooperatif Tipe Student Teams Achievement Division (STAD) Pada Proses Pembelajaran. Jurnal Ilmiah Iqra', 11(1).

B, Fitriani. (2016) PENERAPAN MODEL PEMBELAJARAN KOOPERATIF TIPE STUDENT TEAMS ACHIEVEMENT DIVISION (STAD)
PADA PELAJARAN PKN DI SMA NEGERI 1 WATAN SOPPENG. Hal 50 63.https://sg.docworkspace.com/d/sIPX k7oKKAf_j84Wg.SARI,RP...'KARAK TERISTIK PEMBELAJARAN KOOPERATIF".

http://respository.unpas.ac.id. PDF BAB II.

Agus Suprijono,. (2011) Cooperative Learning; Teori dan Aplikasi PAIKEM (Cet. V; Yogyakarta: Pustaka Pelajar, , h. 133-134. Dikutip oleh

Yusran, moh. abdi. (2012) implementasi model pembelajaran student teams achievement division (stad) pada mata pelajaran Pendidikan agama islam SMP NEGERI 1 SINJAI KABUPATEN SINJAI. Hal 5-7.

Slavin, Robert.E. (2015). Cooperative Learning. Bandung: Penerbit Nusa Media. https://serupa.id/modelpembelajaran-

stad/https://repository.uksw.edu/bitstre am/123456789/11980/3/T1_292010071 _BAB\%20II.pdf

Ariani, T., \& Agustini, D. (2018). Model Pembelajaran Student Team Achievement Division (STAD) dan Model Pembelajaran Teams Games Tournament (TGT): Dampak terhadap Hasil Belajar Fisika. SPEJ (Science and Physic Education Journal), 1(2), 65-77.

Rakhmawan, D. (2014). Penerapan Model Kooperatif Tipe Stad Untuk Meningkatkan Hasil Pada Sekolah Dasar. Jurnal Penelitian Pendidikan Guru Sekolah Dasar, 2(3), 1-10.

Yudiasa, I. K., Dibia, I. K., \& Made Sumantri, M. P. (2016). Penerapan Model Pembelajaran STAD untuk Meningkatkan Motivasi dan Hasil Belajar IPA Kelas V. MIMBAR PGSD Undiksha, 4(3).

Kurniasih, Imas dan Sani, Berlin. (2015). "Ragam Pengembangan Model Pembelajaran untuk Peningkatan Profesionalitas Guru". Jakarta: Kata Pena. https://serupa.id/modelpembelajaran-stad/ 